\title{
Shrimp trade competitiveness of Malaysia and selected ASEAN countries
}

\begin{abstract}
This article investigates the level, composition, and sustainability of the trade competitiveness position of Malaysia among some of the world producers of shrimp commodities in Association of Southeast Asian Nations (ASEAN). The growth rate in the shrimp balance of trade (BOT) surplus had increased the most in Malaysia whereas Singapore recorded the highest growth rate in the shrimp BOT deficit. The trend of the relative trade advantage indices indicates that, among the ASEAN-5, Malaysia and Thailand maintained trade competitiveness in fresh shrimp while Indonesia remained competitive in exporting preserved shrimp. Further, the analytic hierarchy process exerts that Thailand possesses the highest competitiveness ranking in shrimp. To be as competitive as Thailand, Malaysia needs to develop a target area of concentration for shrimp production. This will help the government to introduce and implement policies to mitigate the alleged coastal destructions and environmental pollutions and to provide transparency in the shrimp supply chains.
\end{abstract}

Keyword: Analytic hierarchy process; Environment; Relative trade advantage; Shrimp aquaculture; Target area of concentration 